\title{
Effects of Buprenorphine Maintenance Dose on $\mu$-Opioid Receptor Availability, Plasma Concentrations, and Antagonist Blockade in Heroin-Dependent Volunteers
}

\author{
Mark K Greenwald*,', Chris-Ellyn Johanson', David E Moody ${ }^{2}$, James H Woods ${ }^{3}$, Michael R Kilbourn ${ }^{4}$, Robert \\ A Koeppe ${ }^{4}$, Charles R Schuster' and Jon-Kar Zubieta ${ }^{5}$ \\ 'Substance Abuse Research Division, Department of Psychiatry and Behavioral Neurosciences and Addiction Research Institute, Wayne State \\ University, Detroit, Mi, USA; ${ }^{2}$ Center for Human Toxicology, Department of Pharmacology and Toxicology, University of Utah, Salt Lake City, UT, \\ USA; ${ }^{3}$ Department of Pharmacology, University of Michigan, Ann Arbor, MI, USA; ${ }^{4}$ Department of Internal Medicine, Division of Nuclear \\ Medicine, University of Michigan, Ann Arbor, MI, USA; ${ }^{5}$ Mental Health Research Institute and Departments of Psychiatry and Radiology, \\ University of Michigan, Ann Arbor, MI, USA
}

\begin{abstract}
The clinical effectiveness of opioid maintenance for heroin dependence is believed to result from a medication's ability to decrease $\mu$ opioid receptor $(\mu \mathrm{OR})$ availability thereby replacing agonist effects, alleviating withdrawal symptoms and attenuating heroin effects. We empirically tested this hypothesis in five heroin-dependent volunteers who were successively maintained on $32,16,2$, and 0 mg daily buprenorphine (BUP) tablet doses. We predicted and confirmed that higher BUP doses would decrease in vivo $\mu \mathrm{OR}$ availability (measured with PET and [ ' I C]carfentanil), increase plasma levels of BUP and its metabolite nor-BUP, and decrease withdrawal symptoms and hydromorphone (HYD) responses. Relative to placebo, BUP significantly decreased mean ( \pm SEM) whole-brain $\mu$ OR availability $41 \pm 8,80 \pm 2$, and $84 \pm 2 \%$ at 2, I6, and $32 \mathrm{mg}$, respectively. Regions of interest (ROIs) (prefrontal cortex, anterior cingulate, thalamus, amygdala, nucleus accumbens, caudate) showed similar dose-dependent effects. Changes in $\mu \mathrm{OR}$ availability varied across ROls (prefrontal cortex, 47\% vs amygdala, 27\%) at BUP 2 mg, but were more homogeneous across ROls at BUP 32 mg (94-98\%; except thalamus, $88 \%)$. Relative to placebo $(0 \mathrm{ng} / \mathrm{ml})$, peak plasma levels of BUP and nor-BUP were comparable and dose-dependent (0.5-I, 56 , and $13-14 \mathrm{ng} / \mathrm{ml}$ at 2,16 , and $32 \mathrm{mg}$, respectively). $\mu \mathrm{OR}$ availability decreases were negatively correlated with BUP plasma level and positively correlated with questionnaire-based opioid withdrawal symptoms and attenuation of HYD symptoms. These findings suggest that high-dose BUP maintenance produces near-maximal $\mu \mathrm{OR}$ occupation, $\mu \mathrm{OR}$ availability correlates well with plasma levels, and BUPrelated opioid symptoms and antagonist blockade exhibit concentration-effect relationships.

Neuropsychopharmacology (2003) 28, 2000-2009, advance online publication, 6 August 2003; doi: I0.1038/sj.npp. I30025 I
\end{abstract}

Keywords: buprenorphine; $\mu$-opioid receptor availability; PET; carfentanil; pharmacokinetics; hydromorphone

\section{INTRODUCTION}

Buprenorphine (BUP) is a high-affinity, $\mu$-opioid receptor $(\mu \mathrm{OR})$ partial agonist and $\kappa$-opioid antagonist (Cowan et al, 1977; Heel et al, 1979; Lewis et al, 1983). BUP's $\mu$ OR actions offer agonist substitution (thereby reducing drug use, craving, and withdrawal symptoms) and antagonist blockade (eg subjective high and respiratory toxicity), which can improve treatment outcome (Bickel and Amass,

*Correspondence: Dr Mark Greenwald, Department of Psychiatry and Behavioral Neurosciences, Substance Abuse Research Division, 276I E. Jefferson St., Detroit, MI 48207, USA, Tel: 001 313-993-3965, Fax: 00 I 3|3-993-|372, E-mail: mgreen@med.wayne.edu

Received 23 October 2002; revised I4 May 2003; accepted 23 May 2003

Online publication: 30 May 2003 at http://www.acnp.org/citations/ Npp053002387/default.pdf
1995). Numerous clinical trials support the safety and efficacy of BUP (eg Fudala et al, 1990; Johnson et al, 1995, 2000; Ling et al, 1998), which led to US Food and Drug Administration approval in October 2002 of two sublingual tablet formulations (BUP alone (Subutex ${ }^{\mathrm{TM}}$ ) or combined with naloxone using a 4:1 dose ratio (Suboxone ${ }^{\mathrm{TM}}$ ) to deter parenteral BUP misuse). Unlike other opioid medications (eg methadone), BUP has low oral bioavailability relative to sublingual bioavailability that led to the use of this different route of administration. BUP has a unique pharmacology among opioid medications due to its intermediate intrinsic activity and high affinity at $\mu$ ORs. However, there are presently no in vivo studies of the functional dosedependent relationship between the concentrations of BUP in brain (binding at $\mu$ ORs) with concentration in the peripheral compartment (plasma level) or with symptom effects (ie agonist substitution and withdrawal alleviation) 
and blockade of opioid effects. The present study describes a within-subject multisystem approach to these issues, which may be important for understanding the mechanism of action of drug abuse medications.

A central belief underlying the pharmacotherapy of opioid dependence is that the ability of a medication to occupy brain $\mu$ ORs (which mediate the abuse and dependence potential of opioids) may predict its clinical efficacy. Specifically, higher medication doses are hypothesized to decrease $\mu \mathrm{OR}$ availability (or 'binding potential') and provide agonist replacement that minimizes withdrawal symptoms, promotes clinic attendance, and prevents heroin reinforcement, euphoria, and side effects. At present, this hypothesis is relatively untested for drug abuse medications, and there are many important and interesting questions to address. First, it would be valuable to know the receptor occupancy requirements (ie dose-proportional decrease in receptor availability) of a medication that yields clinically useful effects such as withdrawal alleviation, drug abstinence, or antagonist blockade. Second, plasma levels of a drug are sometimes assumed to proxy for CNS concentrations, but data are sparse as to whether medication plasma levels and receptor availability are linearly related; this is likely to depend on several factors, for example, affinity and biodistribution. Third, the extent of between-subject heterogeneity in receptor availability during medication treatment is not well understood. Characterizing these individual differences, and their relationship with other endpoints may provide theoretically and clinically useful information, for example, whether baseline levels of receptor availability relate to the severity of physical dependence.

Kling et al (2000) reported that heroin-abstaining methadone-maintained patients (30-90 mg/day) had 22$35 \%$ lower opioid receptor availability (measured with positron emission tomography (PET) $22 \mathrm{~h}$ after the last daily dose) than healthy controls. However, that study used $\left[{ }^{18} \mathrm{~F}\right]$ cyclofoxy, a nonselective $\mu$ - and $\kappa$-receptor marker (Carson et al, 1993); therefore, the binding potential measure in that study refers to two receptor populations. As methadone has higher affinity for $\mu \mathrm{OR}$ than $\kappa$-receptor sites (Kristensen et al, 1995), use of a nonselective radiotracer may underestimate $\mu \mathrm{OR}$ availability changes. Fortunately, a $\mu \mathrm{OR}$-selective ligand, $\left[{ }^{11} \mathrm{C}\right]$ carfentanil, has been developed and validated (Frost et al, 1989; Titeler et al, 1989), prompting our use of this radiotracer in the present work. In a preliminary study, we (Zubieta et al, 2000) examined $\mu \mathrm{OR}$ availability in three heroin-dependent volunteers following 12 days of maintenance each on 2 and $16 \mathrm{mg}$ sublingual BUP liquid and after detoxification (6 days maintenance at $0 \mathrm{mg}$ ) under double-blind conditions. In vivo binding potential measures were obtained with $\left[{ }^{11} \mathrm{C}\right]$ carfentanil and PET $4 \mathrm{~h}$ following the daily BUP dose. BUP dose-dependently reduced $\mu \mathrm{OR}$ availability $36-50 \%$ (across regions of interest (ROIs)) at $2 \mathrm{mg}$ and $79-95 \%$ at $16 \mathrm{mg}$ relative to placebo. Decreased $\mu \mathrm{OR}$ availability at the 2 and $16 \mathrm{mg}$ BUP doses paralleled decreases in ratings of heroin craving and opioid withdrawal symptoms.

Pharmacokinetic studies have showed that the BUP sublingual tablet produces peak plasma BUP concentrations that are approximately $50-60 \%$ of the same sublingual liquid doses (Mendelson et al, 1997; Nath et al, 1999; Schuh and Johanson, 1999). This opens the possibility that the occupancy of $\mu \mathrm{OR}$-binding sites might differ between the tablet and liquid formulations. As the tablet will be used clinically, one purpose of the present study was to investigate $\mu \mathrm{OR}$ availability at 2 and $16 \mathrm{mg}$ BUP tablet doses and retrospectively compare the results with our previous study using these same BUP liquid doses (Zubieta et al, 2000). Another pharmacokinetic issue is whether norBUP, the principal metabolite of BUP, might influence (ie additively decrease) $\mu \mathrm{OR}$ availability. Some animal data suggest that nor-BUP may have low brain permeability and that the analgesic potency of nor-BUP is four times less than BUP following i.c.v. administration (Ohtani et al, 1995; Pontani et al, 1985)

Earlier human laboratory studies showed that administration of subcutaneous BUP (Jasinski et al, 1978; Mello et al, 1982) or sublingual BUP liquid (Bickel et al, 1988; Rosen et al, 1994; Walsh et al, 1995) could attenuate the reinforcing, subjective, and physiological effects of $\mu \mathrm{OR}$ agonists. Recent human laboratory studies have demonstrated that daily BUP $16 \mathrm{mg}$ sublingual tablet doses, relative to lower daily tablet doses $(2-8 \mathrm{mg})$, can significantly decrease the reinforcing efficacy of $\mu$-opioids (Comer et al, 2001; Greenwald et al, 2002). An important question that remains, pertaining to BUP's therapeutic efficacy, concerns the functional relationship between $\mu \mathrm{OR}$ occupancy requirements and clinical outcome measures such as opioid withdrawal suppression and antagonist blockade (cf Woods et al, 1992). For this reason, participants in the present BUP maintenance study were given the option to participate in a hydromorphone (HYD) challenge study to determine the correlation between $\mu \mathrm{OR}$ binding, plasma concentrations, and antagonist blockade ability.

The primary goal of the present study was to replicate systematically our previous findings that BUP maintenance dose-dependently reduces $\mu \mathrm{OR}$ availability in vivo (Zubieta et al, 2000). The present study included methodological improvements to extend the scope and significance of these earlier findings. First, we compared data obtained with the BUP tablet to those previously acquired with the liquid formulation. Second, we evaluated changes in $\mu \mathrm{OR}$ binding over a 16-fold range of BUP daily maintenance doses (32, 16 , and $2 \mathrm{mg}$ ), relative to placebo. Third, we measured the plasma concentrations of BUP and its principal metabolite, nor-BUP, in the same individuals at these same BUP doses. Fourth, we studied the ability of BUP to suppress opioid withdrawal symptoms, to attenuate effects of the full $\mu$-agonist HYD, and correlated these changes with brain concentrations of the medication (ie decreased $\mu \mathrm{OR}$ availability in vivo).

\section{METHODS}

\section{Participant Recruiting and Selection}

Institutional Review Boards of Wayne State University and University of Michigan approved all procedures. This study was carried out in accordance with the Declaration of Helsinki as adopted and promulgated by the National Institutes of Health. Heroin-dependent volunteers were recruited from the Detroit area by advertisements and word of mouth. Volunteers provided medical history, blood and 
urine samples, and received an electrocardiogram, tuberculin screening, and a physical examination. Those selected reported no chronic health problems and were not taking prescribed medications. Volunteers were not seeking treatment and were willing to participate in a short-term study involving BUP maintenance and detoxification. An experienced clinician administered a semistructured interview (SCID-IV; First et al, 1996), and opioid dependence severity was determined using the Addiction Severity Index (McLellan et al, 1985a,b). Volunteers were excluded if they met DSM-IV diagnostic criteria for a current Axis I disorder (excluding opioid and nicotine dependence), or were cognitively impaired. During screening, volunteers were required to provide a urine specimen that tested positive for opioids and negative for methadone, benzodiazepines, and barbiturates. Cocaine-positive samples were allowed, but subjects meeting DSM-IV criteria for cocaine abuse or dependence were excluded and could not have cocainepositive urine samples on the days of PET scans (but did not exclude subjects from undergoing HYD challenges). The volunteers were also required to provide an alcohol-free breath sample. After the procedures were fully explained, all volunteers provided written informed consent and were paid in proportion to time of participation. An optional, coordinated study was designed to examine the ability of the different BUP doses to attenuate effects of HYD. Separate informed consent was required for volunteers to participate in the HYD challenge study.

In all, 13 volunteers enrolled in the primary study and, of these, seven discontinued. Four stopped attending the research clinic early in the protocol and were lost to follow-up. We terminated two subjects' participation for unsanctioned drug use. Another experienced an adverse event that may have been an idiosyncratic allergic reaction to carfentanil or HYD. Five (three males and two females) completed all four PET scans and pharmacokinetic evaluations. Three of these five volunteers also completed all four HYD challenge sessions. A sixth participant (female) completed all HYD test procedures, but did not complete the final PET and MRI scans due to withdrawal discomfort. The six participants ranged in age from 34 to 45 years and had completed from 9 to 14 years of education (median $=11.5$ ). Participants reported using heroin from 2 to 20 years (median $=5)$ and spending from $\$ 150$ to $\$ 450$ per week on heroin (median $=\$ 225$ ). The primary route of heroin self-administration was intravenous for three volunteers and intranasal for three volunteers. All participants reported daily use of cigarettes. In the 30 days prior to screening, three participants reported using marijuana at least once, and one reported using cocaine at least once.

\section{Settings and Protocol Timeline}

Figure 1 illustrates the protocol timeline including daily BUP doses and scheduling of outpatient, in-patient, PET, scan and HYD challenge procedures during this 10-week protocol. The participants were initially outpatients for 2 weeks while being stabilized on $32 \mathrm{mg} /$ day BUP. BUP administration took place on an outpatient basis until 4 days prior to each PET scan, when all participants were admitted to an in-patient unit (Monday afternoon until Friday 1100); a subset of these subjects underwent HYD

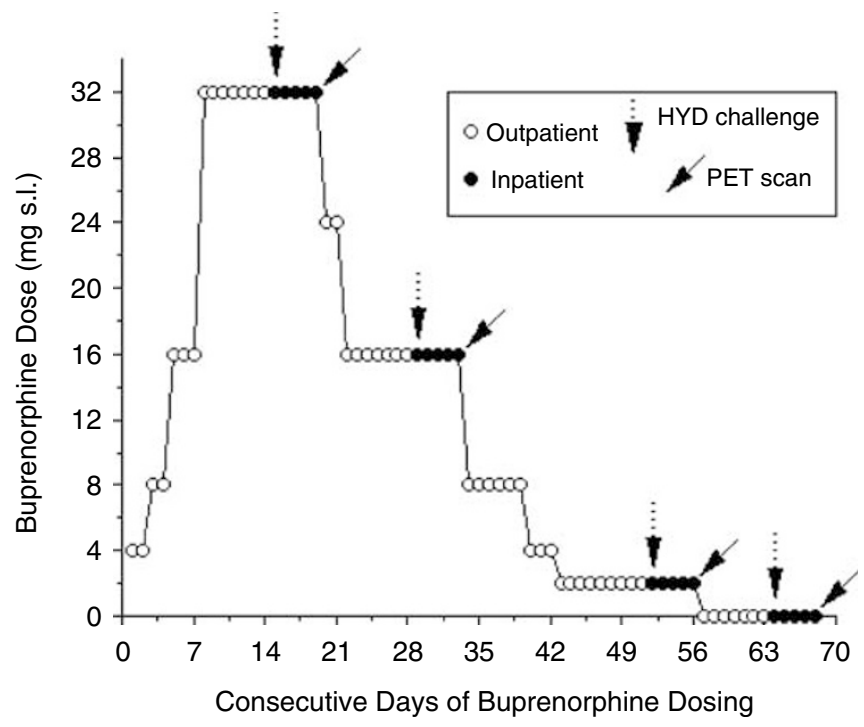

Figure I BUP dosing regimen and timing of outpatient, in-patient, and PET scan procedures during the 10-week study. HYD challenges occurred on the first in-patient day (immediately prior to admission), that is, 4 days before PET scans.

challenges after the BUP dose and immediately prior to admission. At $2 \mathrm{~h}$ after their BUP dose on Friday, participants were discharged from the in-patient unit and transported by taxi with a staff escort to the University of Michigan PET Center. The scan began at about 1300 and took about $90 \mathrm{~min}$. After the PET scan, they were escorted home and resumed outpatient BUP maintenance until the next in-patient admission. This cycle was repeated for each BUP dose evaluation.

\section{Drug Administration}

Buprenorphine. Heroin-dependent participants were maintained on different doses of BUP HCl using combinations of 2 and $8 \mathrm{mg}$ sublingual tablets (without naloxone) and matching placebo tablets (manufactured by Reckitt and Colman, London UK; supplied by Research Triangle Institute, Research Triangle Park, NC, USA). BUP was administered daily at about the same time (always at 0900 during the in-patient stay). BUP tablets (four per day) were held under the tongue until they dissolved. The participant took two tablets at a time while supervised by a research assistant. When the first two tablets dissolved (determined by visual inspection of the mouth), the next two tablets were immediately administered in the same manner. The total dosing time was usually about $10 \mathrm{~min}$. Volunteers received BUP induction doses over 11 days: $4 \mathrm{mg}$ (days 1-2), $8 \mathrm{mg}$ (days 3-4), and $16 \mathrm{mg}$ (days 5-7). Participants were maintained for 12 days on BUP $32 \mathrm{mg}$ (phase 1); 2 days on $24 \mathrm{mg}$; 12 days on $16 \mathrm{mg}$ (phase 2); 6 days on $8 \mathrm{mg}$ and 2 days on $4 \mathrm{mg} ; 14$ days on $2 \mathrm{mg}$ (phase 3); and 12 days on $0 \mathrm{mg}$ (phase 4). The study concluded immediately after the final PET scan. Volunteers were informed that they were fully detoxified and heroin-abstinent, and reminded that they could receive a treatment referral if they wished.

Hydromorphone. HYD challenge sessions were conducted on the eighth maintenance day (Monday) at each BUP dose 
level, immediately before in-patient admission and 4 days prior to each PET scan. HYD (Dilaudid-HP ${ }^{\mathrm{TM}}, 10 \mathrm{mg} / \mathrm{ml}$ ampoules obtained from Knoll Pharmaceuticals, Whippany, $\mathrm{NJ}$, USA) was administered as a single $24 \mathrm{mg}$ i.m. injection into the deltoid muscle (volume $=2.4 \mathrm{ml}$ ).

\section{Measures}

Urinalysis. Observed urine samples for toxicology testing were obtained three times/week (Monday-Wednesday-Friday) during the outpatient period, and daily during each inpatient stay. Semiquantitative analyses of urine samples (see Greenwald, 2002) were performed using fluorescence polarization immunoassay (Abbott $\mathrm{ADx}^{\mathbb{}}{ }^{\mathbb{8}}$ analyzer and standard reagents). These were analyzed for levels of opioids, methadone, cocaine metabolites, benzodiazepines, and barbiturates.

Vital signs and symptom questionnaires. During 2 days (Wednesday-Thursday) of each in-patient stay, vital signs (respiration rate, oral temperature, oxygen saturation, heart rate, and blood pressure) were measured immediately before and at $1,2,3,6$, and $12 \mathrm{~h}$ after daily BUP administration. Opioid symptoms and heroin craving were also rated at these same time points. Opioid agonist and withdrawal symptoms were assessed using a 32-item inventory (Schuster et al, 1995), with 16 Agonist scale items and 16 Withdrawal scale items. Each item was scored on a scale from 0 (not at all) to 4 (extremely), yielding total scores ranging from 0 to 64 . Heroin craving was measured using the Heroin Craving Questionnaire, which is a 45 -item scale with each item scored 1 (strongly disagree) to 7 (strongly agree). Factor analysis of the 45-item responses produced a 34-item factor (Tiffany et al, 1995, unpublished data; see Schuster et al, 1995); the 34-item score has been reported routinely in previous studies. Both the 16-item opioid symptom and 34-item craving questionnaire scores are sensitive to opioid agonist dose-effects (Greenwald $e t$ al, 1999, 2002; Greenwald, 2002) and were used in our earlier $\mu \mathrm{OR}$ neuroimaging study (Zubieta et al, 2000).

During HYD challenge sessions, vital signs and subjective drug effects were measured three times. The following visual analog scale (VAS) ratings were added to the measures above: good drug effect, bad drug effect, liking, stimulated, high, anxious, and sedated. The entire assessment battery took about $45 \mathrm{~min}$ to complete. Session baseline assessments started $45 \mathrm{~min}$ prior to BUP administration. Assessments of post-BUP effects began $1 \mathrm{~h} 30 \mathrm{~min}$ after the BUP dose. HYD was administered $2 \mathrm{~h} 15 \mathrm{~min}$ after the BUP dose and post-HYD assessments began $45 \mathrm{~min}$ later. After completing these test sessions, the participant was escorted to the in-patient unit for admission.

Plasma pharmacokinetics. Blood samples $(8 \mathrm{ml}$ each) were withdrawn from an antecubital vein using a 22-gauge butterfly needle, and collected into 10-ml Vacutainer tubes containing heparin. In all, 10 samples were taken: one immediately before the ninth daily maintenance dose of BUP $(0 \mathrm{~h})$, and at $0.25,0.5,1,2,3,4,6,12$, and $24 \mathrm{~h}$ postBUP. After collection, each tube was inverted several times and centrifuged for $15 \mathrm{~min}$. The plasma was siphoned using plastic, disposable pipettes, placed into plastic cryogenic tubes, and frozen at $-20^{\circ} \mathrm{C}$ prior to analysis. Plasma concentrations of BUP and nor-BUP were determined using liquid chromatography-electrospray ionization-tandem mass spectrometry (Moody et al, 2002). The sensitivity of this method is demonstrated by a $0.1 \mathrm{ng} / \mathrm{ml}$ lower limit of quantitation. The time-to-peak concentration $\left(T_{\max }\right)$, peak concentration $\left(C_{\max }\right)$, and $24-\mathrm{h}$ area under the curve (AUC) values were calculated.

$\mu$ OR-binding measures. Four PET brain scans were conducted at $4 \mathrm{~h}$ after the last of 12 daily doses of BUP 32, $16,2 \mathrm{mg}$, or placebo. Volunteers refrained from cigarette smoking, caffeine, and food intake for $2 \mathrm{~h}$ prior to scanning. Brain images were acquired with a Siemens ECAT EXACT-47 scanner in 3-D mode (intrinsic FWHM resolution $\approx 6 \mathrm{~mm}$ in-plane and $5 \mathrm{~mm}$ in the $z$-axis) with septa retracted. Participants were positioned in the PET scanner gantry using the orbito-meatal line as the reference line, and one intravenous (antecubital) line was placed. A light forehead restraint was used to eliminate intrascan movement. All volunteers also underwent a single high-resolution MRI scan, which was used to coregister PET functional images.

[11C]carfentanil was synthesized at high specific activity ( $>1000 \mathrm{Ci} / \mathrm{mmol}$ ) by the reaction of $11 \mathrm{C}$-methyliodide and a nonmethyl precursor (Dannals et al, 1985), with minor modifications to improve its synthetic yield (Jewett, 2001). Approximately $15 \mathrm{mCi}(555 \mathrm{MBq})$ was administered to each subject per PET scan, with a maximum mass injected of $0.03 \mu \mathrm{g} / \mathrm{kg}$ per study. This ensured that the compound was administered in tracer quantities (receptor occupancy at these tracer doses has been calculated at $0.3-0.6 \%$ for areas of both high and low receptor concentrations). A total of $55 \%$ of the $[11 \mathrm{C}]$ carfentanil dose was administered as a bolus and the remainder as a continuous infusion, using a computer-controlled automated pump to achieve steadystate tracer levels. In all, 16 sets of scans were acquired over 70 min with an increasing duration (30 s up to $10 \mathrm{~min}$ ). Time points were decay-corrected by a calculated method and reconstructed using Hanning 0.5 filtered back-projection, in a $24 \times 24 \mathrm{~cm}$ field of view and a $128 \times 128$ pixel matrix, with scatter correction. Attenuation correction was performed through a 10 -min transmission scan $(68 \mathrm{Ge}$ source) obtained immediately prior to the PET study. Dynamic images were coregistered using automated computer routines (Minoshima et al, 1992).

Image data were transformed, on a pixel-by-pixel basis, into two sets of parametric maps: (1) a tracer transport measure ( $K_{1}$ ratio), which is proportional to cerebral blood flow (tracer transport $=$ blood flow $\times$ extraction) and (2) a receptor-related measure. Tracer transport and binding measures were calculated using a modified Logan graphical analysis (Logan et al, 1996), with the occipital cortex (an area devoid of $\mu$ ORs; Frost et al, 1989) as input function (distribution volume ratio, DVR). The Logan plot becomes sufficiently linear $5 \mathrm{~min}$ after starting radiotracer administration, with a slope proportional to the $\left(B_{\max } / K_{\mathrm{d}}\right)+1$ for this receptor site (Koeppe, 1999), where $B_{\max } / K_{\mathrm{d}}$ is often referred to as the 'binding potential' (BP; Mintun et al, 1984). $K_{\mathrm{d}}$ is assumed to remain constant within subjects; thus, the BP measure is presumed to be directly proportional to the concentration of $\mu \mathrm{ORs}$ in the human brain. 
T1-weighted MR images were then coregistered to the $K_{1}$ images and nonlinear warped to the International Conference in Brain Mapping (ICBM) stereotactic coordinates (Meyer et al, 1997). The transformation matrix was then applied to the $K_{1}$ and DVR images. ROIs of identical size ( $9 \mathrm{~mm}$ diameter spheres) were then localized in the MR images and subsequently transferred to $K_{1}$ and DVR maps. ROIs were placed bilaterally in all regions following Brodmann definitions. BUP did not produce lateralized differences in $\mu \mathrm{OR}$ binding in a previous study (Zubieta et al, 2000); therefore, data for right- and left-sided ROIs were averaged to yield a single regional value. The global binding potential value was calculated using SPM99 (Friston et al, 1995) as the average value across all brain voxels.

\section{Data Analyses}

Data for $\mu \mathrm{OR}$ binding are expressed as the mean \pm 1 SEM for the DVR minus 1 of each ROI (binding potential measure, $\mathrm{BP}=B_{\max } / K_{\mathrm{d}}$ ). We examined different pharmacokinetic indices (eg peak and several AUC post-BUP measures) that were very highly correlated with one another. For simplicity, we used the mean of the 3-h and 4-h post-BUP time points because these data were collected at the same time points as $\mu \mathrm{OR}$ binding estimates. BUP dose-dependent changes in regional $\mu \mathrm{OR}$ binding were examined with one-way univariate repeated measures analyses of variance (ANOVAs) using SuperAnova ${ }^{\mathrm{TM}}$. BUP dose- and time-dependent changes in plasma drug and metabolite levels were evaluated with two-way univariate Dose $\times$ Time repeated measures ANOVAs. Opioid withdrawal and agonist symptoms, heroin craving scores, and vital signs related to BUP administration during two consecutive days of the in-patient stay were analyzed with three-way Dose $\times$ Day $\times$ Time univariate ANOVAs. All analyses used Huynh-Feldt adjustments for violations of sphericity. BUP attenuation of HYD-induced subjective effects and vital signs was examined using post-HYD minus
post-BUP change scores (ie excluding pre-BUP session baseline values), which were entered into one-way BUP Dose ANOVAs. Individual-subject Pearson correlation coefficients were calculated across the four BUP dose conditions to examine associations among the variables. The minimum level of significance in all analyses was set at $p<0.05$.

\section{RESULTS}

\section{Urinalysis}

Urine toxicology testing indicated that participants continued to use opioids during the four outpatient periods, regardless of BUP tablet dose, although self-reported amounts of heroin used decreased by more than half at the two higher maintenance doses. Urinalysis testing of samples collected during each in-patient stay indicated that urine samples of four of the five participants were drug free on the mornings prior to PET scans. Opioid urine levels decreased more slowly for the fifth participant (female) than other participants across in-patient days, testing between 500 and $635 \mathrm{ng} / \mathrm{ml}$ on the mornings of the four PET scans $(300 \mathrm{ng} / \mathrm{ml}$ is the cutoff value for a positive urine in this assay). Nevertheless, we decided to include this subject in the sample because her whole brain and regional $\mu \mathrm{OR}$ availability values were within $10 \%$ of the other subjects and did not meet criteria as an outlier. As $\mu \mathrm{OR}$ availability in this subject was not different relative to other subjects, the changes secondary to BUP administration would not be likely to be heavily influenced by the possible presence of residual opioids and/or slower metabolism.

\section{BUP Effects on $\mu \mathrm{OR}$ Availability}

Compared to the placebo condition, BUP $2 \mathrm{mg}$ decreased $\mu \mathrm{OR}$ availability $27 \%$ (amygdala) to $47 \%$ (prefrontal cortex), with a reduction in whole-brain $\mu \mathrm{OR}$ availability of $41 \%$. Table 1 lists ROI binding potential changes at the $2 \mathrm{mg}$ dose

Table I Mean (SEM) $\mu \mathrm{OR}$ Binding Potential at Placebo and Percentage Changes at Different BUP Maintenance Doses ${ }^{\mathrm{a}}$

\begin{tabular}{|c|c|c|c|c|c|}
\hline \multirow[b]{2}{*}{ Brain region } & \multirow{2}{*}{$\begin{array}{c}B_{\max } / K_{\mathrm{d}} \\
\text { BUP } 0 \mathrm{mg}\end{array}$} & \multicolumn{3}{|c|}{ Percentage changes from BUP placebo } & \multirow{2}{*}{$\begin{array}{l}\text { Dose } \\
F(2,8)\end{array}$} \\
\hline & & BUP 2 mg & BUP $16 \mathrm{mg}$ & BUP $32 \mathrm{mg}$ & \\
\hline Whole brain & $0.69(0.01)$ & $40.6(7.9)$ & $80.2+(2.2)$ & $84.1(1.6)$ & $F=41.4$ \\
\hline Prefrontal cortex (BA I0) & $1.19(0.03)$ & $\begin{array}{l}46.9(8.7) \\
48.1(6.4)\end{array}$ & $\begin{array}{l}89.5(2.6) \\
87.7(5.0)\end{array}$ & $96.2(1.8)$ & $F=41.0$ \\
\hline Subgen. ant. cing. (BA 25) & $1.39(0.04)$ & $\begin{array}{l}45.5(8.9) \\
48.9(0.7)\end{array}$ & $\begin{array}{l}91.5(2.9) \\
85.4(2.8)\end{array}$ & $98.4(1.1)$ & $F=45.8$ \\
\hline Rostral ant. cing. (BA 32) & $1.56(0.04)$ & $\begin{array}{l}44.3(9.6) \\
42.7(2.9)\end{array}$ & $\begin{array}{l}89.7(3.1) \\
85.2(2.4)\end{array}$ & $97.0(1.6)$ & $F=38.0$ \\
\hline Caudate & $1.90(0.15)$ & $\begin{array}{l}40.2(10.6) \\
39.9(4.5)\end{array}$ & $\begin{array}{l}87.3(4.3) \\
84.4(3.3)\end{array}$ & $95.5(1.8)$ & $F=39.0$ \\
\hline Nucleus accumbens & $2.09(0.12)$ & $\begin{array}{l}36.5(8.9) \\
40.3(3.5)\end{array}$ & $\begin{array}{l}85.7(3.0) \\
81.6(4.2)\end{array}$ & $93.8(2.0)$ & $F=62.9$ \\
\hline Thalamus & $1.84(0.08)$ & $\begin{array}{l}36.1(7.7) \\
37.3(5.4)\end{array}$ & $\begin{array}{l}79.5(2.7) \\
78.9(1.9)\end{array}$ & $88.5(1.1)$ & $F=55.5$ \\
\hline Amygdala & $1.57(0.08)$ & $\begin{array}{l}27.0(8.6) \\
35.1(3.5)\end{array}$ & $\begin{array}{l}85.4(2.3) \\
84.1(1.4)\end{array}$ & $96.1(1.6)$ & $F=75.7$ \\
\hline
\end{tabular}

${ }^{a}$ Column I lists the mean $B_{\max } / K_{d}$ value (binding potential) \pm I SEM at the placebo dose. Columns for the three active BUP doses list the mean percentage change $( \pm$ SEM) relative to the placebo value. The first row for each $\mathrm{ROI}$ shows the percent change from placebo using the BUP tablet formulation (present study), whereas the second row shows corresponding data using the BUP liquid formulation and identical PET scanning methods (Zubieta et al, 2000). All F values for BUP doseeffects were significant at $p<0.003$. 
Prefrontal cortex

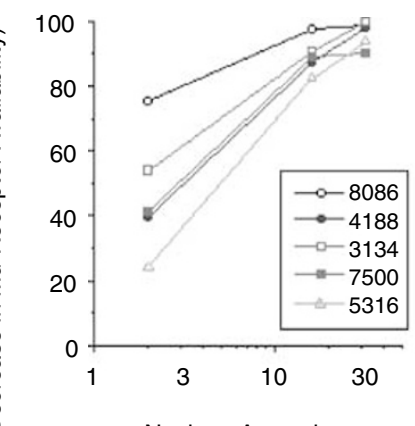

Nucleus Accumbens

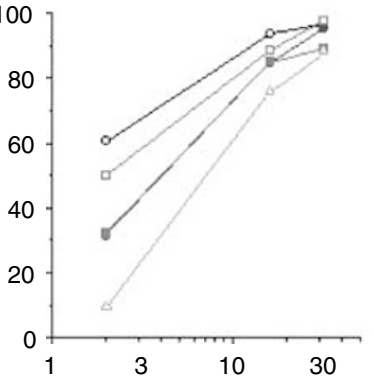

Anterior Cingulate (Subgenual)
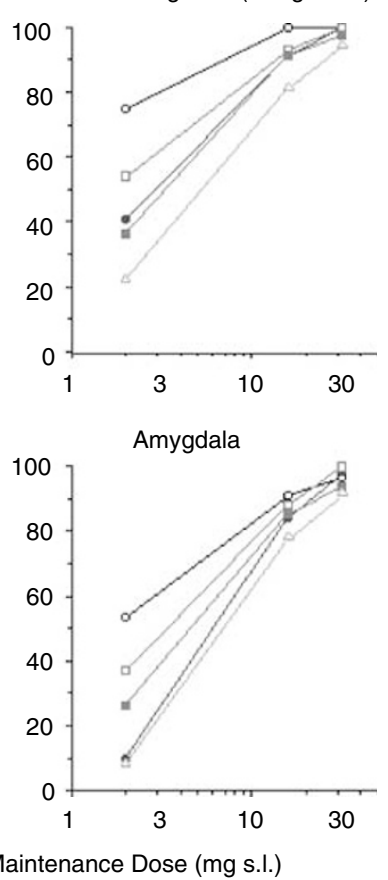

Figure 2 BUP dose-dependently decreased $\mu \mathrm{OR}$ availability for five heroin-dependent participants, as shown in four ROls. Upper left: prefrontal cortex (Brodmann area I I). Upper right: subgenual anterior cingulate (Brodmann area 25). Lower left: nucleus accumbens. Lower right: amygdala. Decreases in availability appear as increasing values on the ordinate because this reflects greater displacement of the $\mu \mathrm{OR}$ radiotracer, [ $\left.{ }^{1} \mathrm{C}\right] \mathrm{carfentanil,}$ by higher BUP doses.

in rank order from high to low. Relative to placebo, BUP $16 \mathrm{mg}$ reduced $\mu \mathrm{OR}$ availability $85-92 \%$, and BUP $32 \mathrm{mg}$ decreased $\mu$ OR availability $94-98 \%$. $\mu$ OR binding potential of BUP at these two higher doses was more consistent across ROIs, although the thalamus showed slightly less reduction. Significant dose-dependent decreases in $\mu \mathrm{OR}$ availability were demonstrated for whole-brain estimates and all ROIs. Least square post hoc testing indicated that, for all ROIs, mean $\mu \mathrm{OR}$ availability significantly differed between all doses except for the $32 v s 16 \mathrm{mg}$ comparisons (which never differed from one another). As shown in Figure 2, interindividual variability was marked at the BUP $2 \mathrm{mg}$ dose (up to six-fold, depending on the ROI), whereas interindividual variability was minimal for the BUP 16 and $32 \mathrm{mg}$ conditions. Figure 3 illustrates clear dose-related changes in $\mu \mathrm{OR}$ availability for all ROIs for one representative subject (\#7500; also see Figure 2).

To examine the comparability of changes in $\mu \mathrm{OR}$ availability produced by liquid and tablet formulations of BUP, we compared binding changes from the present study with those obtained in our previous report (Zubieta et al, 2000). Data for the 2 and $16 \mathrm{mg}$ doses were examined using percent change from placebo (the $32 \mathrm{mg}$ dose was not administered in the earlier study). $\mu \mathrm{OR}$ binding in the ROIs was obtained using identical procedures for both sets of data. Analyses of variance indicated no Formulation or Formulation $\times$ Dose effects for any ROI (all $p$ 's $>0.30$ ), indicating no significant differences in $\mu \mathrm{OR}$ binding change between the BUP tablet and liquid delivery systems. Table 1 enables the reader to compare the $\mu \mathrm{OR}$ binding values for these doses across the two formulations.

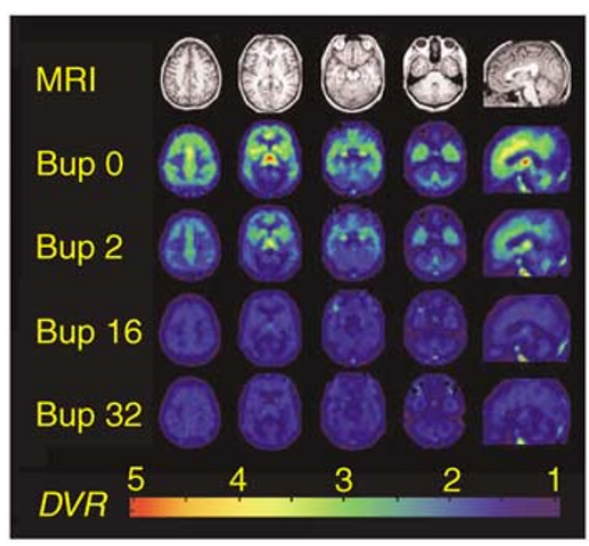

Figure 3 Parametric images of $\mu \mathrm{OR}$ availability $\left(B_{\max } / K_{d}\right.$; extracted from Logan plot slopes with the occipital cortex as the input function) from a representative heroin-dependent volunteer (\#7500; see Figure 2) during daily maintenance on BUP placebo (row 2), $2 \mathrm{mg}$ (row 3), $16 \mathrm{mg}$ (row 4), and $32 \mathrm{mg}$ (row 5). Images are scaled so that binding in the occipital cortex, an area devoid of $\mu$ receptors, is equal to I. Four transverse sections (from superior (column I) to inferior (column 4)) and one sagittal section (column 5) are shown, which correspond to TI-weighted anatomical MRI images (row I). The pseudocolor scale depicts DVR values from I to 4.

\section{Plasma Concentrations during BUP Maintenance}

Figure 4 depicts dose- and time-dependent changes in BUP and nor-BUP plasma concentrations during maintenance at each BUP dose level. BUP and nor-BUP plasma concentrations generally peaked at $1 \mathrm{~h}$, but nor-BUP levels tended to reach peak $\left(T_{\max }\right)$ values slightly later. Peak concentrations 


\begin{tabular}{ccccccc} 
& \multicolumn{2}{c}{ BUPRENORPHINE } & & \multicolumn{2}{c}{ NOR-BUPRENORPHINE } \\
BUP Dose & Tmax $(\mathrm{hr})$ & Cmax $(\mathrm{ng} / \mathrm{ml})$ & AUC $\left(\mathrm{ng} / \mathrm{ml}{ }^{*} \mathrm{hr}\right)$ & Tmax $(\mathrm{hr})$ & Cmax $(\mathrm{ng} / \mathrm{ml})$ & \multicolumn{1}{c}{ AUC $\left(\mathrm{ng} / \mathrm{ml}{ }^{*} \mathrm{hr}\right)$} \\
\hline $2 \mathrm{mg}$ & $0.9+0.1$ & $0.3+0.1$ & $6.5+1.6$ & $1.6+0.4$ & $0.7+0.2$ & $14.0+8.8$ \\
$16 \mathrm{mg}$ & $1.2+0.2$ & $6.3+0.9$ & $48.6+8.0$ & $1.4+0.4$ & $5.4+1.3$ & $87.3+23.1$ \\
$32 \mathrm{mg}$ & $1.2+0.2$ & $13.2+4.2$ & $96.0+16.1$ & $1.6+0.2$ & $14.2+2.9$ & $168.0+31.0$
\end{tabular}
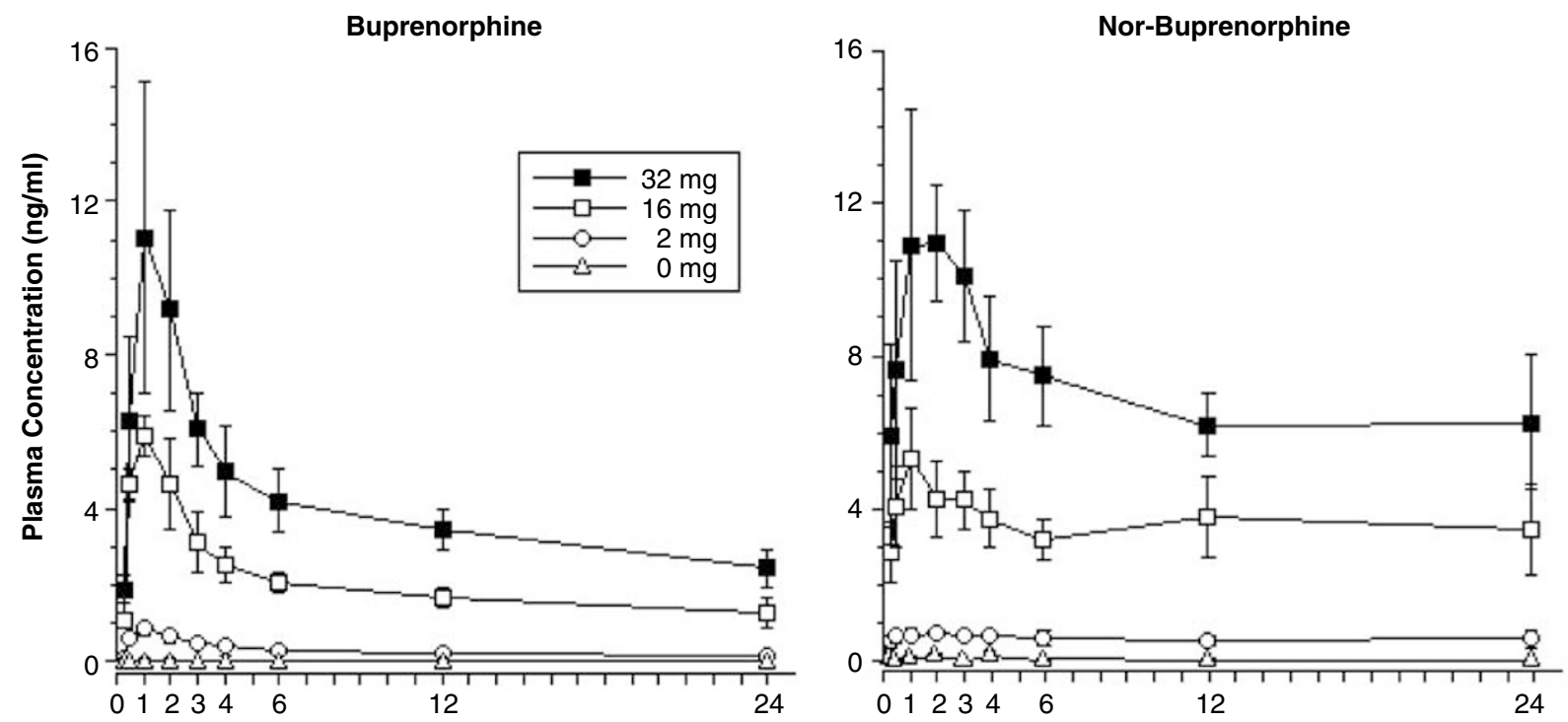

Time Since Buprenorphine (Hours)

Figure 4 Mean ( \pm SEM) dose- and time-dependent changes in plasma concentrations ( $\mathrm{ng} / \mathrm{ml}$ ) of BUP (left panel) and its metabolite nor-BUP (right panel) over a 24-h blood sampling period in five heroin-dependent volunteers maintained on 32, 16,2 , and $0 \mathrm{mg} /$ day BUP. Time to peak ( $T_{\text {max }}$ ), peak value $\left(C_{\max }\right)$, and AUC measures are shown in the table inset. With the 0-mg doses coming after prolonged BUP maintenance, there existed the possibility of residual drug or metabolite being present; accordingly, these samples were also subjected to analysis. BUP was not detected in any sample and is displayed as $0 \mathrm{ng} / \mathrm{ml}$; nor-BUP was occasionally found in quantifiable amounts, resulting in mean values slightly in excess of 0 ng/ml. For BUP plasma levels, there were significant effects of Dose, $F(3,96)=22.48, p<0.01$, and Time, $F(8,96)=9.66, p<0.005$, but no significant Dose $\times$ Time interaction ( $p<0.07)$. For nor-BUP plasma levels, there were significant effects of Dose, $F(3,96)=21.27, p<0.01$, and Time, $F(8,96)=3.68, p<0.04$, but no significant interaction $(p<0.13$ ). Least squares post hoc testing indicated that mean BUP and nor-BUP plasma levels significantly differed from one another at all doses except between 2 mg and placebo.

$\left(C_{\max }\right)$ of BUP and nor-BUP at each maintenance dose were similar. However, nor-BUP accumulated more than BUP from 2- to 24-h following the daily dose, as indicated by the roughly two-fold higher AUC values for nor-BUP.

\section{BUP-Related Opioid Symptoms}

The first two rows of data in Table 2 present opioid withdrawal and agonist symptom scores during BUP maintenance. The average withdrawal scores on day 1 (but not day 2) of the in-patient stay significantly increased during maintenance on BUP placebo and $2 \mathrm{mg}$ daily doses relative to the two higher maintenance doses. Average opioid agonist scores on days 1-2 of the in-patient stay tended to increase at higher BUP doses, but this was not significant. There were no other significant effects for symptom measures (eg heroin craving) or vital signs related to BUP dose during the in-patient stays.

\section{BUP Antagonist Blockade of HYD Subjective Effects}

The last three rows of data in Table 2 present HYD-induced changes in opioid subjective effects during the different BUP maintenance doses. Relative to placebo and BUP $2 \mathrm{mg}$, the two high BUP doses significantly decreased the ability of HYD to increase opioid agonist symptom scores and drug 'high'. A similar, but nonsignificant, trend was observed for 'good drug effect'. There were no other trends for subjective drug effects.

\section{Functional Relationships among Measures}

To assess BUP dose-dependent relationships, mean values for medication concentrations and effects were correlated across the four BUP dose levels; these are presented in Table 3. Variables of interest were whole-brain $\mu \mathrm{OR}$ binding; plasma level of BUP (3-4h post-BUP, when $\mu \mathrm{OR}$ availability was measured); opioid agonist and withdrawal symptoms, and heroin craving during BUP maintenance (in the absence of HYD); and HYD-induced subjective and physiological effects. $\mu$-receptor binding and BUP plasma levels were significantly related. $\mu \mathrm{OR}$ availability was significantly and positively related to baseline withdrawal symptoms and heroin craving, and negatively related to opioid agonist symptoms. There were correlations of similar magnitude (but opposite sign) between BUP plasma levels and these subjective measures. Finally, greater $\mu \mathrm{OR}$ 
Table 2 Mean (+SEM) Effects of BUP Dose on Baseline Opioid Symptoms and HYD-Induced Change $(\Delta)$ in Subjective Effects

\begin{tabular}{lccccc}
\hline Measure & BUP 0 mg & BUP 2 mg & BUP 16 mg & BUP 32 mg & Dose-effect \\
\hline Withdrawal (day I) & $17.1(1.8)^{\mathrm{a}}$ & $10.0(1.5)^{\mathrm{ab}}$ & $4.0(0.9)^{\mathrm{b}}$ & $3.6(0.7)^{\mathrm{b}}$ & $\mathrm{F}(3,12)=5.01, p<0.02$ \\
Agonist (days I-2) & $6.1(0.4)$ & $7.5(0.5)$ & $8.1(0.6)$ & $9.2(0.6)$ & $\mathrm{F}(3,12)=3.31, p<0.08$ \\
$\Delta$ Agonist & $14.8(2.6)^{\mathrm{a}}$ & $13.0(1.6)^{\mathrm{a}}$ & $3.5(1.3)^{\mathrm{b}}$ & $4.0(1.7)^{\mathrm{b}}$ & $\mathrm{F}(3,9)=8.77, p<0.005$ \\
$\Delta$ High & $57.0(8.3)^{\mathrm{a}}$ & $69.0(10.3)^{\mathrm{a}}$ & $19.0(10.5)^{\mathrm{b}}$ & $37.3(9.5)^{\mathrm{ab}}$ & $\mathrm{F}(3,9)=5.14, p<0.03$ \\
$\Delta$ Good Effect & $55.8(15.0)$ & $49.0(20.0)$ & $15.8(9.5)$ & $9.8(6.5)$ & $\mathrm{F}(3,9)=3.41, p<0.07$ \\
\hline
\end{tabular}

Note: Means $(n=4)$ that have different letters significantly differ, whereas means that share a letter do not differ significantly.

Table 3 Relationships Between BUP Concentrations ( $\mu$ OR Availability ${ }^{a}$ and Plasma Levels ${ }^{b}$ ) and Effects (Baseline Opioid Symptoms ${ }^{c}$ and Antagonist Blockade of HYD Response ${ }^{d}$ ) Across BUP Doses

\begin{tabular}{|c|c|c|c|c|c|c|c|}
\hline & Plasma level & \multicolumn{3}{|c|}{ BUP-related (baseline) opioid symptoms } & \multicolumn{3}{|c|}{ HYD subjective responses } \\
\hline $\begin{array}{l}\mu O R \text { availability } \\
\text { BUP plasma level }\end{array}$ & $-0.859 *$ & $\begin{array}{r}0.998^{*} \\
-0.834^{*}\end{array}$ & $\begin{array}{r}-0.946 * \\
0.931 *\end{array}$ & $\begin{array}{r}0.997 * \\
-0.872 *\end{array}$ & $\begin{array}{r}0.890 \\
-0.825\end{array}$ & $\begin{array}{r}0.534 \\
-0.494\end{array}$ & $\begin{array}{r}0.864 \\
-0.922\end{array}$ \\
\hline
\end{tabular}

${ }^{a} \mu \mathrm{OR}$ availability refers to mean $(n=5)$ whole-brain absolute $B_{\text {max }} / K_{d}$ values. Similar results were obtained when separate Pearson correlation coefficients were computed between $\mu \mathrm{OR}$ availability in brain $\mathrm{ROls}$ and the other measures.

blasma level is the mean $(n=5)$ BUP concentration averaged from the 3-and 4-h post-BUP time points, that is at the same post-BUP time that $\mu$ OR availability was measured.

'Mean $(n=5)$ opioid withdrawal, agonist symptom and heroin craving measures represent the average questionnaire scores across two in-patient hospitalization days of BUP maintenance, independent of HYD challenges.

'HYD responses are the mean pre- to post-HYD change scores for total agonist symptoms, and VAS ratings of drug 'high' and 'good effect'. These data were available for three participants, and correlations of this measure with $\mu \mathrm{OR}$ binding potential and BUP plasma levels were computed only for these three subjects. Significance of these correlation coefficients was not determined due to the small sample size.

availability and lower plasma levels (at lower BUP doses) was related to greater HYD subjective effects (ie less antagonist blockade). However, due to the small number of subjects, the significance of these latter correlations could not be assessed.

\section{DISCUSSION}

This study replicates and extends previous findings (Zubieta et al, 2000) that BUP, a newly approved medication for heroin abuse, dose-dependently binds in vivo to human brain $\mu$ ORs, which mediate the reinforcing and physical dependence-producing effects of heroin. A major aim of this study was to assess the relationship between the concentrations of BUP in the brain ( $\mu \mathrm{OR}$ occupancy) and periphery (plasma levels) across doses for each participant. Plasma levels are sometimes assumed to serve as a proxy for brain levels, but this assumption has rarely been evaluated. Another aim was to assess the magnitude of relationships of both $\mu \mathrm{OR}$ binding and plasma levels to clinically relevant opioid symptom effects.

Daily BUP tablet maintenance produced substantial doserelated decreases in $\mu \mathrm{OR}$ binding, reaching nearly complete ( $>90 \%$ ) occupancy of most ROI receptor sites. The tablet doses that produced these large changes in $\mu \mathrm{OR}$ binding potential are roughly similar to BUP liquid doses that have been shown to be clinically effective in treatment studies (Bickel and Amass, 1995; Johnson et al, 2000; Ling et al, 1998; Schottenfeld et al, 1993). The mean $\mu \mathrm{OR}$ binding potential values for the $32 \mathrm{mg} /$ day dose were higher than, but did not significantly differ from, the $16 \mathrm{mg} /$ day BUP dose. Binding changes produced by the $2 \mathrm{mg}$ dose were lower and more variable across subjects, consistent with our previous data (Zubieta et al, 2000). The present study also found significant dose- and time-dependent changes in plasma concentrations of BUP and its metabolite, nor-BUP. Peak plasma levels of BUP and nor-BUP were similar shortly after the daily maintenance dose, whereas nor-BUP accumulated more during the 24-h sampling period than BUP. These peak BUP plasma levels produced by daily tablet doses of $16 \mathrm{mg}(6.3 \mathrm{ng} / \mathrm{ml})$ and $2 \mathrm{mg}(0.3 \mathrm{ng} / \mathrm{ml})$ were higher and lower, respectively, than peak BUP plasma levels produced by the $8 \mathrm{mg}$ tablet in this laboratory $(3 \mathrm{ng} / \mathrm{ml}$; Schuh and Johanson, 1999). Therefore, the present findings are internally and externally consistent.

Using the BUP plasma concentration from $4 \mathrm{~h}$ postadministration, which corresponds to when $\mu \mathrm{OR}$ availability was measured with PET, individual-subject correlation coefficients between these two measures were high, albeit imperfect, during steady-state maintenance. Similar relationships between $\mu \mathrm{OR}$ binding and drug plasma concentration were obtained using alternative pharmacokinetic indices, including the sum of BUP and nor-BUP levels. One explanation for the observed correlations is that the binding estimates in the present study could involve a three-way competition among BUP, nor-BUP, and tracer doses of $\left[{ }^{11} \mathrm{C}\right]$ carfentanil used to measure receptor concentrations, that is, such that competition from nor-BUP would weaken the relationship. However, data suggest that nor-BUP has limited access to the brain (Ohtani et al, 1995; Pontani et al, 1985). As the present study allowed for washout of illicit heroin (and other drugs) and as nor-BUP probably has little influence, it appears that BUP is the principal compound competing with $\left[{ }^{11} \mathrm{C}\right]$ carfentanil when measuring $\mu \mathrm{OR}$ availability in the present study. One potential reason for the imperfect linear association between BUP levels in brain ( $\mu \mathrm{OR}$ availability) and periphery (plasma concentration) 
could reflect hysteresis (ie a nonlinear relationship) due to the high affinity of BUP at $\mu$ ORs.

To compare the extent of $\mu \mathrm{OR}$ occupancy across BUP sublingual liquid and tablet formulations, this study included tablet doses of 2 and $16 \mathrm{mg}$ thereby matching our previous study using the same liquid doses and PET scanning procedures (Zubieta et al, 2000). This comparison is of interest because pharmacokinetic data (Mendelson et al, 1997; Nath et al, 1999; Schuh and Johanson, 1999) suggest that bioavailability of the BUP tablet is about 40 $50 \%$ lower than the liquid formulation. Inspection of data for individual ROIs found close agreement at each dose across studies except for the amygdala, which (due to its small size) is subject to partial volume averaging effects and lower signal-to-noise ratios. Statistical comparison of BUPinduced $\mu \mathrm{OR}$ availability changes in this study and the previous one found no significant differences between the liquid and tablet formulations. These findings suggest that the BUP liquid $v s$ tablet formulation potency differences previously observed for plasma levels may not apply to brain concentrations. The fact that the liquid and tablet produced similar reductions in opioid withdrawal symptoms at each dose in both studies further supports this conclusion. Although this comparison produced encouragingly similar data, the conclusions are necessarily limited by the small sample sizes used in each study. Specifically, caution should be exercised-especially at low BUP doses (or high receptor availability levels) - because the lack of statistical difference (ie apparent similarity) in mean $\mu \mathrm{OR}$ availability across BUP formulations could be masked by large standard deviations.

Results of this study support a previous finding of an inverse relationship between BUP plasma levels and withdrawal symptoms (Kuhlman et al, 1998). The present study similarly showed that $\mu \mathrm{OR}$ availability was also strongly related to withdrawal symptoms. Other subjective effects measures (eg agonist symptoms, craving) were also significantly correlated with these biological measures of BUP concentration. These data demonstrate a direct (within-subject, dose-response) relationship between in vivo human brain receptor binding and clinical symptoms produced by a drug abuse medication, which has long been assumed to occur, but not previously tested in humans. The final aim of this study was to begin exploring the relationship between decreased $\mu \mathrm{OR}$ availability or higher plasma concentrations and the ability of BUP (a partial $\mu \mathrm{OR}$ agonist) to exhibit functional antagonism of the effects of HYD. For participants who contributed to this preliminary assessment, HYD effects were attenuated as predicted. Furthermore, albeit the sample size was small and precluded statistical evaluation, the ability of BUP to bind to $\mu$ ORs was positively related to its antagonist blockade of HYD subjective effects.

In conclusion, the novel findings of this study are as follows: the BUP tablet dose-dependently decreased in vivo $\mu \mathrm{OR}$ availability (replicating previous results with the BUP liquid formulation), increased plasma levels of BUP and its metabolite nor-BUP, decreased opioid withdrawal symptoms, and attenuated HYD effects. $\mu \mathrm{OR}$ binding dosedependently correlated with plasma levels, withdrawal symptoms, and blockade of HYD agonist symptoms. This study integrates information across these multiple levels of analyses, helping to characterize the pharmacodynamic actions of BUP and improve understanding of the functional relationships among clinically relevant endpoints.

\section{ACKNOWLEDGEMENTS}

USPHS Grants P50 DA00254 and R01 DA10100 from the National Institute on Drug Abuse and a research grant (Joe Young, Sr) from the State of Michigan supported this research.

We thank Dr John Hopper for medical oversight, Ken Bates for recruitment, Ja'Near Mathis for urine testing, Nancy Lockhart, Teresa Woike, and Suzanne Manji for scheduling, and Debra Kish, Rebecca Cohn, and Josh Bueller for data management. We thank the staff of the Neuropsychiatric Research Unit at Wayne State University for blood sample and clinical data collection and observation.

\section{REFERENCES}

Bickel WK, Amass L (1995). Buprenorphine treatment of opioid dependence: a review. Exp Clin Psychopharmacol 3: 477-489.

Bickel WK, Stitzer ML, Bigelow GE, Liebson IA, Jasinski DR, Johnson RE (1988). Buprenorphine: dose-related blockade of opioid challenge effects in opioid dependent humans. J Pharmacol Exp Ther 247: 47-53.

Carson RE, Channing MA, Blasberg RG, Dunn BB, Cohen RM, Rice $\mathrm{KC}$ et al (1993). Comparison of bolus and infusion methods for receptor quantification: application to $\left[{ }^{18} \mathrm{~F}\right]$ cyclofoxy and positron emission tomography. J Cereb Blood Flow Metab 13: $24-42$.

Comer SD, Collins ED, Fischman MW (2001). Buprenorphine sublingual tablets: effects on IV heroin self-administration by humans. Psychopharmacology 154: 28-37.

Cowan A, Lewis JW, Macfarlane IR (1977). Agonist and antagonist properties of buprenorphine: a new antinociceptive agent. $\mathrm{Br} J$ Pharmacol 60: 537-545.

Dannals RF, Ravert HT, Frost JJ, Wilson AA, Burns HD, Wagner Jr HN (1985). Radiosynthesis of an opiate receptor binding radiotracer: [11C]carfentanil. Int J Appl Radiat Isot 36: 303-306.

First MB, Spitzer RL, Gibbon M, Williams JBW (1996). Structured Clinical Interview for DSM-IV Axis Disorders-Patient Edition (SCID-I/P, Version 2.0). Biometrics Research Department, NY State Psychiatric Institute: New York.

Friston KJ, Holmes AP, Worsley KJ, Poline JB, Frith CD, Frackowiak RSJ (1995). Statistical parametric maps in functional neuroimaging: A general linear approach. Hum Brain Map 2: 189-210.

Frost JJ, Douglass KH, Mayberg HS, Dannals RF, Links JM, Wilson AA et al (1989). Multicompartmental analysis of $\left[{ }^{11} \mathrm{C}\right]$ carfentanil binding to opiate receptors in humans measured by positron emission tomography. J Cereb Blood Flow Metab 9: 398-409.

Fudala PJ, Jaffe JH, Dax EM, Johnson RE (1990). Use of buprenorphine in the treatment of opioid addiction. II. Physiologic and behavioral effects of daily and alternate-day administration and abrupt withdrawal. Clin Pharmacol Ther 47: 525-534.

Greenwald MK (2002). Heroin craving and drug use in opioidmaintained volunteers: effects of methadone dose variations. Exp Clin Psychopharmacol 10: 39-46.

Greenwald MK, Johanson CE, Schuster CR (1999). Opioid reinforcement in heroin-dependent volunteers during buprenorphine maintenance. Drug Alcohol Depend 56: 191-203. 
Greenwald MK, Schuh KJ, Hopper JA, Schuster CR, Johanson CE (2002). Effects of buprenorphine sublingual tablet maintenance on opioid drug-seeking behavior by humans. Psychopharmacology 160: $344-352$.

Heel RC, Brogdon RN, Speight TM, Avery GS (1979). Buprenorphine: a review of its pharmacological properties and therapeutic efficacy. Drugs 17: 81-110.

Jasinski DR, Pevnick JS, Griffith JD (1978). Human pharmacology and abuse potential of the analgesic buprenorphine. Arch Gen Psychiatry 35: 501-506.

Jewett DM (2001). A simple synthesis of [11C]carfentanil. Nucl Med Biol 28: 733-734.

Johnson RE, Chutuape MA, Strain EC, Walsh SL, Stitzer ML, Bigelow GE (2000). A comparison of levomethadyl acetate, buprenorphine, and methadone for opioid dependence. $N$ Engl J Med 343: 1290-1297.

Johnson RE, Eissenberg T, Stitzer ML, Strain EC, Liebson IA, Bigelow GE (1995). A placebo controlled clinical trial of buprenorphine as a treatment for opioid dependence. Drug Alcohol Depend 40: 17-25.

Kling MA, Carson RE, Borg L, Zametkin A, Matochik JA, Schluger J et al (2000). Opioid receptor imaging with positron emission tomography and $[18 \mathrm{~F}]$ cyclofoxy in long-term, methadonetreated former heroin addicts. J Pharmacol Exp Ther 295: 1070-1076.

Koeppe RA (1999). Data analysis for PET studies of neuroreceptor modulation. J Nucl Med 5, 287pp.

Kristensen K, Christensen CB, Christrup LL (1995). The mu1, mu2, delta, kappa opioid receptor binding profiles of methadone stereoisomers and morphine. Life Sci 56: 45-50.

Kuhlman Jr JJ, Levine B, Johnson RE, Fudala PJ, Cone EJ (1998). Relationship of plasma buprenorphine and norbuprenorphine to withdrawal symptoms during dose induction, maintenance, and withdrawal from sublingual buprenorphine. Addiction 93: 549-559.

Lewis JW, Rance MJ, Sanger DJ (1983). The pharmacology and abuse potential of buprenorphine: a new antagonist analgesic. In: Mello NK (ed). Advances in Substance Abuse Vol. 3 JAI Press: Greenwich, 103-154.

Ling W, Charuvastra C, Collins JF, Batki S, Brown Jr LS, Kintaudi $\mathrm{P}$ et al (1998). Buprenorphine maintenance treatment of opiate dependence: a multicenter, randomized clinical trial. Addiction 93: 475-486.

Logan J, Fowler JS, Volkow ND, Wang G-J, Ding Y-S, Alexoff DL (1996). Distribution volume ratios without blood sampling from graphical analysis of PET data. J Cereb Blood Flow Metab 16: 834-840.

McLellan AT, Luborsky L, Cacciola J, Griffith J, Evans F, Barr HL et al (1985a). New data from the Addiction Severity Index. J Nerv Ment Dis 173: 412-423.

McLellan AT, Luborsky L, O’Brien CP (1985b). Improved diagnostic instrument for substance abuse patients: The Addiction Severity Index. J Nerv Ment Dis 168: 26-33.

Mello NK, Mendelson JH, Kuehnle JC (1982). Buprenorphine effects on human heroin self-administration: an operant analysis. J Pharmacol Exp Ther 223: 30-39.

Mendelson J, Upton RA, Everhart ET, Jacob P, Jones RT (1997). Bioavailability of sublingual buprenorphine. J Clin Pharmacy 37: 31-37.

Meyer CR, Boes JL, Kim B, Bland PH, Zasadny KR, Kison PV et al (1997). Demonstration of accuracy and clinical versatility of mutual information for automatic multimodality image fusion using affine and thin-plate spline warped geometric deformations. Med Image Anal 1: 195-206.

Minoshima S, Berger KL, Lee KS, Mintun MA (1992). An automated method for rotational correction and centering of three-dimensional functional brain images. J Nucl Med 33: 1579-1585.

Mintun MA, Raichle ME, Kilbourn MR, Wooten GF, Welch MJ (1984). A quantitative model for the in vivo assessment of drug binding sites with positron emission tomography. Ann Neurol 15: $217-227$

Moody DE, Slawson MH, Strain EC, Laycock JD, Spanbauer AC, Foltz RL (2002). A liquid chromatographic-electrospray ionization-tandem mass spectrometric method for determination of buprenorphine, its metabolite, norbuprenorphine, and a coformulant, naloxone, that is suitable for in vivo and in vitro metabolism studies. Anal Biochem 306: 31-39.

Nath RP, Upton RA, Everhart ET, Cheung P, Shwonek P, Jones RT et al (1999). Buprenorphine pharmacokinetics: relative bioavailability of sublingual tablet and liquid formulations. J Clin Pharmacol 39: 619-623.

Ohtani M, Kotaki H, Sawada Y, Iga T (1995). Comparative analysis of buprenorphine- and norbuprenorphine-induced analgesic effects based on pharmacokinetic-pharmacodynamic modeling. $J$ Pharmacol Exp Ther 272: 505-510.

Pontani RB, Vadlamani NL, Misra AL (1985). Disposition in the rat of buprenorphine administered parenterally and as a subcutaneous implant. Xenobiotica 15: 287-297.

Rosen MI, Wallace EA, McMahon TJ, Pearsall HR, Woods SW, Price LH et al (1994). Buprenorphine: duration of blockade of effects of intramuscular hydromorphone. Drug Alcohol Depend 35: 141-149.

Schottenfeld RS, Pakes J, Ziedonis D, Kosten TR (1993). Buprenorphine: dose-related effects on cocaine and opioid use in cocaine-abusing opioid-dependent humans. Biol Psychiatry 34: $66-74$

Schuh KJ, Johanson CE (1999). Pharmacokinetic comparison of the buprenorphine sublingual liquid and tablet. Drug Alcohol Depend 56: 55-60.

Schuster CR, Greenwald MK, Johanson CE, Heishman SJ (1995). Measurement of drug craving during naloxone-precipitated withdrawal in methadone maintained volunteers. Exp Clin Psychopharmacol 3: 424-431.

Tiffany ST, Fields L, Singleton E, Haertzen C, Henningfield JE (1995, unpublished data). The development of a heroin craving questionnaire.

Titeler M, Lyon RA, Kuhar MJ, Frost JF, Dannals RF, Leonhardt S et al (1989). $\mathrm{Mu}$ opiate receptors are selectively labelled by $[3 \mathrm{H}]$ carfentanil in human and rat brain. Eur J Pharmacol 167: 221-228.

Walsh SL, Preston KL, Bigelow GE, Stitzer ML (1995). Acute administration of buprenorphine in humans: partial agonist and blockade effects. J Pharmacol Exp Ther 274: 361-372.

Woods JH, France CP, Winger GD (1992). Behavioral pharmacology of buprenorphine: issues relevant to its potential in treating drug abuse. NIDA Res Monogr 121: 12-27.

Zubieta JK, Greenwald MK, Lombardi U, Woods JH, Kilbourn MR, Jewett DM et al (2000). Buprenorphine-induced changes in $\mathrm{mu}$ opioid receptor availability in male heroin-dependent volunteers: a preliminary study. Neuropsychopharmacology 23: 326-334. 